\title{
VIBRATION AND STABILITY OF TWO TUBES IN CROSSFLOW*
}

\author{
by
}

S. Zhu, S. S. Chen, and Y. Cai

Energy Technology Division

Argonne National Laboratory

Argonne, Illinois 60439

The submitted manuscript has been authored by a
contractor of the U.S. Government under contract No.
W-31-109-ENG-38. Accordingly, the U. S.
Government retains a nonexclusive, royalty-free
license to publish or reproduce the publlshed form of
this contribution, or allow others to do so, for U.S.
Govemment purposes.

\section{MASTER}

For publication in the Journal of Acoustical Society of America.

*This work was jointly funded by the U.S. Department of Energy, Office of Basic Energy Sciences, Division of Engineering and Geosciences, under Contract W-31109-Eng-38, and by Taiwan Power Company under an agreement with the U.S. Department of Energy, Contract Agreement 31-109-Eng-38-85847. 


\title{
VIBRATION AND STABILITY OF TWO TUBES IN CROSSFLOW
}

\author{
S. Zhu, S. S. Chen, and Y. Cai \\ Energy Technology Division \\ Argonne National Laboratory \\ Argonne, Illinois
}

\section{ABSTRACT}

Two tubes in tandem and normal to flow were studied on the basis of the unsteady-flow theory. Motion-dependent fluid forces were measured in a water channel, and the pitch-to-diameter ratio was 1.35. From the measured fluid forces, fluid damping and stiffness were calculated as a function of reduced flow velocity and several Reynolds numbers. Once the fluid-damping and fluid-stiffness coefficients are known, coupled vibration and stability of the two tubes in crossflow can be predicted.

\section{INTRODUCTION}

Flow-induced vibration of two tubes in crossflow has been studied extensively, including vibration in stationary fluid, turbulent buffeting, vortex-induced vibration, and wake-induced flutter. Several reviews were published by Chen (1986) and Zdravkovich (1977).

The flow field around two tubes is very complex and depends on Reynolds number and tube arrangement, as well as on conditions of incoming flow. The interaction of fluid flow with tube oscillation is even more complicated. Various approximate theories have been developed to describe the tube response in crossflow. At this time, it remains difficult to predict the response of the two tubes 
because the fluid forces acting on the tubes and the motion-dependent fluid forces cannot be calculated with confidence.

On the basis of the available information, the general characteristics of tube response in crossflow are not well understood in the various parameter ranges, because most of the experimental data were obtained for specific applications. A systematic study is needed to quantify the response of two tubes under different flow conditions. The objective of this paper is to present an unsteady flow theory for two tubes normal to the flow and two tubes in tandem, with a pitch-to-diameter ratio of 1.35 (see Fig. 1, where $D$ is tube diameter).

For two tubes oscillating in crossflow, the fluid forces acting on the tubes are $f_{i}$ and $g_{i}(i=1,2)$ in the $x$ and $y$ directions. The corresponding tube displacement components of the tubes are $u_{i}$ and $v_{j}$. Fluid forces acting on the tube due to the tube motion are given by Chen (1987) as

$$
\begin{aligned}
f_{j}= & -\rho \pi R^{2} \sum_{k=1}^{2}\left(\alpha_{j k} \frac{\partial^{2} u_{k}}{\partial t^{2}}+\sigma_{j k} \frac{\partial^{2} v_{k}}{\partial t^{2}}\right)+\frac{\rho U^{2}}{\omega} \sum_{k=1}^{2}\left(\alpha_{j k}^{\prime} \frac{\partial u_{k}}{\partial t}+\sigma_{j k}^{\prime} \frac{\partial v_{k}}{\partial t}\right) \\
& +\rho U^{2} \sum_{k=1}^{2}\left(\alpha_{j k}^{\prime \prime} u_{k}+\sigma_{j k}^{\prime \prime} v_{k}\right)
\end{aligned}
$$

and

$$
\begin{aligned}
g_{j}= & -\rho \pi R^{2} \sum_{k=1}^{2}\left(\tau_{j k} \frac{\partial^{2} u_{k}}{\partial t^{2}}+\beta_{j k} \frac{\partial^{2} v_{k}}{\partial t^{2}}\right)+\frac{\rho U^{2}}{\omega} \sum_{k=1}^{2}\left(\tau_{j k}^{\prime} \frac{\partial u_{k}}{\partial t}+\beta_{j k}^{\prime} \frac{\partial v_{k}}{\partial t}\right) \\
& +\rho U^{2} \sum_{k=1}^{2}\left(\tau_{j k}^{\prime \prime} u_{k}+\beta_{j k}^{\prime \prime} v_{k}\right),
\end{aligned}
$$


where $\rho$ is fluid density; $R$ is tube radius; $t$ is time; $\omega$ is circular frequency of tube oscillations; $U$ is flow velocity; $\alpha_{\mathrm{jk}}, \beta_{\mathrm{jk}}, \sigma_{\mathrm{jk}}$, and $\tau_{\mathrm{jk}}$ are added mass coefficients; $\alpha_{\mathrm{jk}}$, $\beta_{\mathrm{jk}}^{\prime}, \sigma_{\mathrm{jk}}^{\prime}$, and $\tau_{\mathrm{jk}}^{\prime}$ are fluid-damping coefficients; and $\alpha_{\mathrm{jk}}^{\prime \prime}, \beta_{\mathrm{jk}}^{\prime \prime}, \sigma_{\mathrm{jk}}^{\prime \prime}$, and $\tau_{\mathrm{jk}}^{\prime \prime}$ are fluid-stiffness coefficients. The main purpose of this study is to measure the motion-dependent fluid-force coefficients for two tubes in crossflow. Once these fluid-force coefficients are obtained, tube response in various conditions can be analyzed on the basis of the unsteady-flow theory.

It should be noted that Eqs. 1 and 2 look linear. However, fluid-force coefficients, in general, are functions of Reynolds number, tube oscillation amplitude, and oscillation frequency. Therefore, fluid forces given in Eqs. 1 and 2 in fact are nonlinear as long as the force coefficients are not considered as constants.

\section{EXPERIMENTAL SETUP}

The two tubes tested are shown in Fig. 1, where the tubes are normal to flow (Fig. 1a) or in tandem (Fig. 1b). A water channel 18 in. wide and 15 in. deep is used. Water is pumped into an input tank and then passes through a series of screens and honeycombs and finally into the rectangular channel. Water level is controlled by standpipes in the output tank, and flow is controlled by the speed of the pump motor.

Flow velocity is measured with a current flow meter. The rate of propeller rotation is directly proportional to stream velocity and therefore the sensor output signal is not affected by other factors such as water conductivity, temperature, or suspended particulates.

Tubes are supported by flexible tubes attached to the stainless steel tubes with a $2.54-\mathrm{cm}$ outer diameter (OD), a $0.071-\mathrm{cm}$ wall thickness, and a $38.1-\mathrm{cm}$ length. 
Two sets of strain gauges are placed on the outer surface of the smaller tube where the outer surface of the tube has been machined to give an octagonal cross section; the details have been published earlier (Chen, Zhu, and Jendrzejczyk 1994). These tubes are used as force transducers. The natural frequencies of the tubes are as follows:

\begin{tabular}{cccc}
\hline \multirow{2}{*}{ Tube No. } & Total Mass $(\mathrm{g})$ & \multicolumn{2}{c}{ Natural Frequencies $(\mathrm{Hz})$} \\
\cline { 3 - 4 } & & $\mathrm{x}$ Direction & y Direction \\
\hline 1 & 194 & 9.9 & 11.6 \\
2 & 198 & 10.3 & 10.3 \\
\hline
\end{tabular}

The force transducers are calibrated by the dynamic method. The tube is connected to an exciter and is excited at a given frequency and amplitude in air or water. Then, the inertia forces due to the sinusoidal oscillations are used to determine the calibration constant.

\section{COUPLED VIBRATION IN STATIONARY FLUID}

When two tubes are positioned with a pitch-to-diameter of 1.35 , fluid coupling can be significant. The fluid coupling effect can be accounted for using the added mass matrices (Chen 1975). The added mass was calculated from the potential-flow theory, and experiments were performed to confirm the theoretical results from the indirect measurement method of the effect of natural frequencies for tubes submerged in fluid (Chen and Jendrzejczyk 1978).

In this study, a direct method is used to quantify the effect of fluid coupling. In stationary fluid, $U=0$; Eqs. 1 and 2 can be written as 


$$
\begin{aligned}
& f_{j}=-\rho \pi R^{2} \sum_{k=1}^{2}\left(\alpha_{j k} \frac{\partial^{2} u_{k}}{\partial t^{2}}+\sigma_{j k} \frac{\partial^{2} v_{k}}{\partial t^{2}}\right)+\rho \pi R^{2} \omega \sum_{k=1}^{2}\left(\bar{\alpha}_{j k}^{\prime} \frac{\partial u_{k}}{\partial t}+\bar{\sigma}_{j k}^{\prime} \frac{\partial v_{k}}{\partial t}\right), \\
& g_{j}=-\rho \pi R^{2} \sum_{k=1}^{2}\left(\tau_{j k} \frac{\partial^{2} u_{k}}{\partial t^{2}}+\beta_{j k} \frac{\partial^{2} v_{k}}{\partial t^{2}}\right)+\rho \pi R^{2} \omega \sum_{k=1}^{2}\left(\bar{\tau}_{j k}^{\prime} \frac{\partial u_{k}}{\partial t}+\bar{\beta}_{j k}^{\prime} \frac{\partial v_{k}}{\partial t}\right)
\end{aligned}
$$

where $\bar{\alpha}_{j k}^{\prime}, \bar{\beta}_{j k}^{\prime}, \bar{\sigma}_{j k}^{\prime}$, and $\bar{\tau}_{j k}^{\prime}$ are fluid-damping coefficients in stationary fluid. The theoretical values of the added mass coefficients for two tubes normal to flow with pitch-to-diameter ratio of 1.35 are given as follows:

$$
\begin{aligned}
& {\left[\begin{array}{ll}
\alpha_{11} & \alpha_{12} \\
\alpha_{21} & \alpha_{22}
\end{array}\right]=\left[\begin{array}{cc}
1.0526 & -0.2845 \\
-0.2845 & 1.0526
\end{array}\right]} \\
& {\left[\begin{array}{ll}
\beta_{11} & \beta_{12} \\
\beta_{21} & \beta_{22}
\end{array}\right]=\left[\begin{array}{ll}
1.0526 & 0.2845 \\
0.2845 & 1.0526
\end{array}\right]} \\
& \tau_{j k}=\sigma_{j k}=0, \quad j, k=1,2 .
\end{aligned}
$$

In stationary fluid, added mass can be determined by measuring the forces acting on the tubes due to a sinusoidal excitation. Figures 2a-2d show force components $f_{i}$ and $g_{i}$ due to the excitation of $u_{1}$ (Fig. 2e). It is noted that $f_{1}$ and $g_{2}$ are approximately in phase with $\mathrm{u}_{1}$, while $\mathrm{f}_{2}$ and $\mathrm{g}_{1}$ are approximately out of phase with $\mathrm{u}_{1}$. From the time histories and Eqs. 3 and 4, the added mass coefficients, $\alpha_{j k}$ $\beta_{j k}, \sigma_{j k}$, and $\tau_{j k}$ and damping coefficients, $\bar{\alpha}_{j k}^{\prime}, \bar{\beta}_{j k}^{\prime}, \bar{\sigma}_{j k}^{\prime}$, and $\bar{\tau}_{j k}^{\prime}$, can be calculated. Figure 3 shows the experimental data of the added mass and fluid-damping coefficients as a function of excitation amplitude at three frequencies ( $f$ ). The measured added mass coefficients, $\alpha_{11}$ and $\alpha_{21}$, agree well with the analytical solution. Fluid-damping coefficients in stationary fluid are small. In this case, $\sigma_{j k}$ and $\tau_{j k}$ are zero theoretically and approximately zero experimentally. This direct measurement method can be used to measure added mass and fluid damping efficiently. 


\section{MOTION-DEPENDENT FLUID FORCES}

The unsteady flow theory is used in this study. If tube 1 is excited in the $x$ direction, its displacement is given by

$$
\mathrm{u}_{1}=\mathrm{u} \cos \omega \mathrm{t}
$$

The fluid force acing on the two tubes can be written

$$
\begin{aligned}
& f_{1}=\frac{1}{2} \rho U^{2} c_{11} u \cos \left(\omega t+\phi_{11}\right), \\
& f_{2}=\frac{1}{2} \rho U^{2} c_{21} u \cos \left(\omega t+\phi_{21}\right), \\
& g_{1}=\frac{1}{2} \rho U^{2} d_{11} u \cos \left(\omega t+\psi_{11}\right), \\
& g_{2}=\frac{1}{2} \rho U^{2} d_{21} u \cos \left(\omega t+\psi_{21}\right),
\end{aligned}
$$

where $c_{11}, c_{21}, d_{11}$, and $d_{21}$ are coefficients and $\phi_{11}, \phi_{21}, \psi_{11}$, and $\psi_{21}$ are phase angles. From Eqs. 1, 2, and 6, we can also write the fluid-force components as

$$
\begin{aligned}
& \mathrm{f}_{1}=\left(\rho \pi \mathrm{R}^{2} \omega^{2} \alpha_{11}+\rho \mathrm{U}^{2} \alpha_{11}^{\prime \prime}\right) \mathrm{u} \cos \omega \mathrm{t}-\rho \mathrm{U}^{2} \alpha_{11}^{\prime} \mathrm{u} \sin \omega \mathrm{t}, \\
& \mathrm{f}_{2}=\left(\rho \pi \mathrm{R}^{2} \omega^{2} \alpha_{21}+\rho \mathrm{U}^{2} \alpha_{21}^{\prime \prime}\right) \mathrm{u} \cos \omega \mathrm{t}-\rho \mathrm{U}^{2} \alpha_{21}^{\prime} \mathrm{u} \sin \omega \mathrm{t}, \\
& \mathrm{g}_{1}=\left(\rho \pi \mathrm{R}^{2} \omega^{2} \tau_{11}+\rho \mathrm{U}^{2} \tau_{11}^{\prime \prime}\right) \mathrm{u} \cos \omega \mathrm{t}-\rho \mathrm{U}^{2} \tau_{11}^{\prime} \mathrm{u} \sin \omega \mathrm{t}, \\
& \mathrm{g}_{2}=\left(\rho \pi \mathrm{R}^{2} \omega^{2} \tau_{21}+\rho \mathrm{U}^{2} \tau_{21}^{\prime \prime}\right) \mathrm{u} \cos \omega t-\rho \mathrm{U}^{2} \tau_{21}^{\prime} \mathrm{u} \sin \omega \mathrm{t} .
\end{aligned}
$$


Comparing Eqs. 7 and 8 yields

$$
\begin{aligned}
& \alpha_{11}^{\prime \prime}=\frac{1}{2} c_{11} \cos \phi_{11}-\frac{\pi^{3}}{\mathrm{U}_{\mathrm{r}}^{2}} \alpha_{11}, \\
& \alpha_{21}^{\prime \prime}=\frac{1}{2} c_{21} \cos \phi_{21}-\frac{\pi^{3}}{\mathrm{U}_{\mathrm{r}}^{2}} \alpha_{21}, \\
& \tau_{11}^{\prime \prime}=\frac{1}{2} \mathrm{~d}_{11} \cos \psi_{11}-\frac{\pi^{3}}{\mathrm{U}_{\mathrm{r}}^{2}} \tau_{11}, \\
& \tau_{21}^{\prime \prime}=\frac{1}{2} \mathrm{~d}_{21} \cos \psi_{21}-\frac{\pi^{3}}{\mathrm{U}_{\mathrm{r}}^{2}} \tau_{21},
\end{aligned}
$$

and

$$
\begin{array}{ll}
\alpha_{11}^{\prime}=\frac{1}{2} c_{11} \sin \phi_{11}, & \alpha_{21}^{\prime}=\frac{1}{2} c_{21} \sin \phi_{21}, \\
\tau_{11}^{\prime}=\frac{1}{2} d_{11} \sin \psi_{11}, & \tau_{21}^{\prime}=\frac{1}{2} d_{21} \sin \psi_{21} .
\end{array}
$$

Other fluid-force coefficients can be measured by exciting tube 1 in the y direction and tube 2 in the $x$ and $y$ directions.

The following tests have been performed:

- Two tubes normal to flow (Fig. 1a): Tube 1 was excited in the $x$ and $y$ directions. 
- Two tubes in tandem (Fig. 1b): The upstream tube (tube 1) and the downstream tube (tube 2) are excited in the $\mathrm{x}$ and $\mathrm{y}$ directions.

In each test, the excitation frequency ranges from 0.1 to $2.3 \mathrm{~Hz}$. For two tubes normal to flow, five flow velocities are tested: $0.05,0.07,0.113,0.146$, and $0.166 \mathrm{~m} / \mathrm{s}$. For all other tests, three flow velocities are tested: $0.07,0.11$, and $0.15 \mathrm{~m} / \mathrm{s}$. The corresponding Reynolds numbers are $1250(0.05 \mathrm{~m} / \mathrm{s}), 1750(0.07 \mathrm{~m} / \mathrm{s}), 2830(0.113$ $\mathrm{m} / \mathrm{s}), 3660(0.146 \mathrm{~m} / \mathrm{s}), 3760(0.15 \mathrm{~m} / \mathrm{s})$, and $4160(0.166 \mathrm{~m} / \mathrm{s})$. In all tests, when the flow speed was set at $0.15 \mathrm{~m} / \mathrm{s}$, different excitation levels were given to determine the fluid-force coefficients as a function of excitation level.

Fluid-damping and fluid-stiffness coefficients are obtained for two tubes normal to flow and two tubes in tandem. The following data are available:

- Two Tubes Normal to Flow: Fluid-force coefficients due to the motion of tube 1 in the $\mathrm{x}$ and $\mathrm{y}$ directions.

- Two Tubes in Tandem: Fluid-force coefficients due to the motion of tube 1 in the $\mathrm{x}$ and $\mathrm{y}$ directions and due to the motion of tube 2 in the $\mathrm{x}$ and $\mathrm{y}$ directions.

To limit the length of this paper, only the data for two tubes normal to flow are presented (Figs. 4-9). Readers interested in additional data can contact the authors for additional force coefficients.

Note that Figs. 4-7 show the fluid-force coefficients as a function of reduced flow velocity at several flow velocities, while Figs. 8 and 9 show the fluid-force coefficients as a function of excitation level. 
From the data, some general characteristics of motion-dependent fluid-force coefficients are noticed:

\section{High Reduced Flow Velocity}

When the reduced flow velocity, $U_{\mathrm{r}}(=\mathrm{U} / \mathrm{fD}$; $f$ is the oscillation frequency of the cylinder in flow and $D=2 R$ ), is high, e.g., $>20$ and some $>10$, all fluid-force coefficients are approximately independent of reduced flow velocity. This shows that when the flow velocity is high relative to cylinder velocity, the fluid forces resulting from tube motion can be quantified at a specific velocity and the results can be applied to other flow velocities. In this range, measurements of fluid forces can be significantly reduced. This characteristic is not only valid for circular cylinders, but also for other geometries (Chen and Chandra 1991).

\section{Reynolds Number}

At low reduced flow velocity, fluid-force coefficients depend on the reduced flow velocity, Reynolds number, and excitation amplitude. Similar characteristics have been noticed for a single cylinder (Chen, Zhu, and Cai 1995). This can be seen from the results given in Figs. 4-9. For example, the coefficients for $U_{r}<8$ are shown in Fig. 10. The peak values decrease with flow velocity and are shifted toward larger $\mathrm{U}_{\mathrm{r}}$. This trend is similar to those of a single tube. At lower reduced flow velocity, fluid-force coefficients are much more complicated.

Questions may be raised on the reliability of the force transducers. The motion-dependent fluid forces may be very small. Are the force transducers sensitive enough to measure these forces? Three different force transducers were designed and tested. The force transducers used in this test were found to be 
reliable. This can be seen from the comparison of the added mass coefficients in stationary fluid; the measured values and theoretical results agree very well.

In the figures, fluid-force coefficient curves are plotted by simply connecting the experimental points. There are many lumps and bumps in these curves. There are several possibilities such as experimental uncertainty and metastable flow (Zdravkovich 1991). At this time, it is difficult to pinpoint the exact cause of each bump. It is recognized that force transducers developed for this test are not perfect; however, with perfect force transducers, it would still not be possible to generate a fluid-force coefficient curve without bumps in some flow regimes because the flow is bistable. The data will depend of the flow regime.

In this study, due to the capacity of the water channel, tests were performed for Reynolds number from about 1200 to 4200 . This is lower than the Reynolds numbers in many practical cases. From test results, it is noted that fluid-force coefficients are a function of Reynolds number at lower reduced flow velocity range. Additional tests are needed to quantify fluid forces at higher Reynolds numbers.

\section{DYNAMIC RESPONSE OF TWO TUBES IN CROSSFLOW}

Consider two identical tubes with radius $R$ subjected to crossflow, as shown in Fig. 11. The axes of the tube are parallel to the z-axis and flow is parallel to the $x$-axis. The subscript $j$ is used to denote variables associated with tube $j$. Variables associated with the motion in the $\mathrm{x}$ and $\mathrm{y}$ directions are flexural rigidity $\mathrm{EI}$, cylinder mass per unit length $\mathrm{m}$, structural damping coefficient $\mathrm{C}_{\mathrm{s}}$, and displacement $\mathrm{u}_{j}$ and $\mathrm{v}_{\mathrm{j}}$. The equations of motion for tube $\mathrm{j}$ in the $\mathrm{x}$ and $\mathrm{y}$ directions are (Chen 1987) 


$$
\begin{gathered}
\mathrm{EI} \frac{\partial^{4} u_{j}}{\partial z^{4}}+C_{s} \frac{\partial u_{j}}{\partial t}+m \frac{\partial^{2} u_{j}}{\partial t^{2}}+\sum_{k=1}^{2} \rho \pi R^{2}\left(\alpha_{j k} \frac{\partial^{2} u_{k}}{\partial t^{2}}+\sigma_{j k} \frac{\partial^{2} v_{k}}{\partial t^{2}}\right) \\
-\sum_{k=1}^{2}\left(\frac{\rho U^{2}}{\omega} \alpha_{j k} \frac{\partial u_{k}}{\partial t}+\frac{\rho U^{2}}{\omega} \sigma_{j k}^{\prime} \frac{\partial v_{k}}{\partial t}\right) \\
-\sum_{k=1}^{2} \rho U^{2}\left(\alpha_{j k}^{\prime \prime} u_{k}+\sigma_{j k}^{\prime \prime} v_{k}\right)=f_{j} \\
E I \frac{\partial^{4} v_{j}}{\partial z^{4}}+C_{s} \frac{\partial v_{j}}{\partial t}+m \frac{\partial^{2} v_{j}}{\partial t^{2}}+\sum_{k=1}^{2} \rho \pi R^{2}\left(\tau_{j k} \frac{\partial^{2} u_{k}}{\partial t^{2}}+\beta_{j k} \frac{\partial^{2} v_{k}}{\partial t^{2}}\right) \\
-\sum_{k=1}^{2}\left(\frac{\rho U^{2}}{\omega} \tau_{j k}^{\prime} \frac{\partial u_{k}}{\partial t}+\frac{\rho U^{2}}{\omega} \beta_{j k}^{\prime} \frac{\partial v_{k}}{\partial t}\right) \\
-\sum_{k=1}^{2} \rho U^{2}\left(\tau_{j k}^{\prime \prime} u_{k}+\beta_{j k}^{n}\right)=g_{j},
\end{gathered}
$$

where $f_{j}$ and $g_{j}$ are the excitation forces. Note that fluid-damping coefficients and fluid-stiffness coefficients are functions of reduced flow velocity $U_{r}$.

The in-vacuum variables are mass per unit length $\mathrm{m}$, modal damping ratio $\zeta_{\mathrm{v}}$ and natural frequency $f_{\mathrm{v}}\left(=\omega_{\mathrm{v}} / 2 \pi\right)$. The values for $\mathrm{f}_{\mathrm{v}}$ and $\zeta_{\mathrm{v}}$ can be calculated from the equation of motion and appropriate boundary conditions or from tests in vacuum (practically, in air). The modal function of the cylinder vibrating in vacuum and in fluid is $\psi(z)$;

$$
\frac{1}{\ell} \int_{0}^{1} \psi^{2}(\mathrm{z}) \mathrm{dz}=1
$$

where $\ell$ is the length of the cylinders. Let 


$$
\begin{aligned}
& u_{j}(z, t)=a_{j}(t) y(z), \\
& v_{j}(z, t)=b_{j}(t) y(z),
\end{aligned}
$$

where $a_{j}(t)$ and $b_{j}(t)$ are functions of time only. Calculation of Eqs. 11 and 12 yields

$$
\begin{aligned}
& \ddot{\mathrm{a}}_{\mathrm{j}}+\gamma \sum_{\mathrm{k}=1}^{2}\left(\alpha_{\mathrm{jk}} \ddot{\mathrm{a}}_{\mathrm{k}}+\sigma_{\mathrm{jk}} \ddot{\mathrm{b}}_{\mathrm{k}}\right)+2 \zeta_{\mathrm{v}} \omega_{\mathrm{v}} \dot{\mathrm{a}}_{\mathrm{j}}-\frac{\gamma}{\pi^{3}} \mathrm{U}_{\mathrm{v}}^{2}\left(\frac{\omega_{\mathrm{v}}^{2}}{\omega}\right)_{\mathrm{k}=1}^{2}\left(\alpha_{\mathrm{jk}}^{\prime} \dot{\mathrm{a}}_{\mathrm{k}}+\sigma_{\mathrm{jk}} \dot{\mathrm{b}}_{\mathrm{k}}\right) \\
& \quad+\omega_{\mathrm{v}}^{2} \mathrm{a}_{\mathrm{j}}-\frac{\gamma}{\pi^{3}} \mathrm{U}_{\mathrm{v}}^{2} \omega_{\mathrm{v}}^{2} \sum_{\mathrm{k}=1}^{2}\left(\alpha_{\mathrm{jk}}^{\prime \prime} \mathrm{a}_{\mathrm{k}}+\sigma_{\mathrm{jk}}^{n} \mathrm{~b}_{\mathrm{k}}\right)=\mathrm{p}_{\mathrm{j}} \\
& \ddot{\mathrm{b}}_{\mathrm{j}}+\gamma \sum_{\mathrm{k}=1}^{2}\left(\tau_{\mathrm{jk}} \ddot{\mathrm{a}}_{\mathrm{k}}+\beta_{\mathrm{jk}} \dot{\mathrm{b}}_{\mathrm{k}}\right)+2 \zeta_{\mathrm{v}} \omega_{\mathrm{v}} \dot{\mathrm{b}}_{\mathrm{j}}-\frac{\gamma}{\pi^{3}} \mathrm{U}_{\mathrm{v}}^{2}\left(\frac{\omega_{\mathrm{v}}^{2}}{\omega}\right) \sum_{\mathrm{k}=1}^{2}\left(\tau_{\mathrm{jk}}^{\prime} \dot{\mathrm{a}}_{\mathrm{k}}+\beta_{\mathrm{jk}} \dot{\mathrm{b}}_{\mathrm{k}}\right) \\
& \quad+\omega_{\mathrm{v}}^{2} \mathrm{~b}_{\mathrm{j}}-\frac{\gamma}{\pi^{3}} \mathrm{U}_{\mathrm{v}}^{2} \omega_{\mathrm{v}}^{2} \sum_{\mathrm{k}=1}^{2}\left(\tau_{\mathrm{jk}}^{n} \mathrm{a}_{\mathrm{k}}+\beta_{\mathrm{jk}}^{n} \mathrm{~b}_{\mathrm{k}}\right)=\mathrm{q}_{\mathrm{j}},
\end{aligned}
$$

where the dot denotes differentiation with respect to time and,

$$
\begin{aligned}
& U_{v}=\frac{U}{f_{v} D}, \\
& \gamma=\frac{\rho \pi R^{2}}{m}, \\
& p_{j}=\frac{1}{m \ell} \int_{0}^{\ell} f_{j} \psi(z) d z, \\
& q_{j}=\frac{1}{m \ell} \int_{0}^{\ell} g_{j} \psi(z) d z .
\end{aligned}
$$




\section{Constrained Modes}

When one of the tubes is allowed to oscillate in a specific direction while the other tubes are rigid, the equations of motion can be simplified significantly. For example, when tube 1 oscillates in the $\mathrm{x}$ direction, its equation of motion based on Eq. 15 becomes

$$
\frac{d^{2} a_{j j}}{d t^{2}}+2 \zeta \omega \frac{d a_{i j}}{d t}+\omega^{2} a_{j j}=\frac{p_{j}}{1+\gamma \alpha_{j j}}
$$

where

$$
\begin{aligned}
& \omega=\omega_{\mathrm{v}}\left(1+\gamma \mathrm{C}_{\mathrm{M}}\right)^{-0.5}, \\
& \zeta=\frac{\zeta_{\mathrm{v}}}{1+\gamma \alpha_{\mathrm{jj}}}\left[\left(1+\gamma \mathrm{C}_{\mathrm{M}}\right)^{0.5}-\frac{\gamma \mathrm{U}_{\mathrm{r}}^{2} \alpha_{\mathrm{ji}}^{\prime}}{2 \zeta_{\mathrm{v}} \pi^{3}}\right], \\
& \mathrm{C}_{\mathbf{M}}=\alpha+\frac{\mathrm{U}_{\mathrm{r}}^{2} \alpha_{\mathrm{jj}}^{\prime \prime}}{\pi^{3}} .
\end{aligned}
$$

Note that $\omega$ and $\zeta$ are the circular frequency and modal damping ratio, respectively, for the tube in crossflow. $\mathrm{CM}_{\mathrm{M}}$ is called an added mass coefficient for the tube in flow; when $U_{r}=0$, it is equal to $\alpha_{j j}$. When $U_{r}$ is not equal to zero, $C_{M}$ depends on $U_{r}$ as well as on $\alpha_{j j}^{\prime \prime}$, which in turn, depends on $U_{r}$ and oscillation amplitude.

From Eqs. 19 it is noted that when $\alpha_{j}$ is positive, it will contribute to negative damping to the system. In some cases, the resultant damping may become zero and the system will become unstable. From Eq. 19 the critical reduced flow velocity at which the modal damping ratio is zero can be calculated from 


$$
\mathrm{U}_{\mathrm{r}}=4 \sqrt{2 \pi}\left(\frac{\delta}{\alpha_{\mathrm{jj}}^{\prime}}\right)^{0.5}\left[\frac{\delta}{\pi^{2}}\left(\frac{\alpha_{\mathrm{jj}}^{\prime \prime}}{\alpha_{\mathrm{jj}}^{\prime}}\right) \pm \sqrt{\left(\frac{\delta}{\pi^{3}}\right)^{2}+\frac{1+\gamma \alpha_{\mathrm{jj}}}{4}}\right]^{0.5},
$$

where $\delta$ is a mass-damping parameter $\left(\delta=2 \pi \zeta_{\mathrm{v}} \mathrm{m} / \rho \mathrm{D}^{2}\right)$. This is the critical flow velocity for fluidelastic instability.

Equations $18-20$ can also be applied to oscillations in the y direction. Replacing all $\alpha$ by $\beta$ in Eqs. 18-20 yields the equations of motion and stability criterion for constrained mode in the y direction. From Eqs. 19 and 20, it is noted that when the value of the fluid-damping coefficient, $\alpha_{j j}^{\prime}$ or $\beta_{j j}$, is positive, the tube may become unstable. The region depends on tube arrangement, location, and flow velocity. From the fluid-force coefficients, $\alpha_{j \mathrm{j}}^{\prime}$ is found to be positive in the regions given in Table 1. Fluid-damping coefficients in the $y$ direction $\beta_{11}^{\prime}$ and $\beta_{22}^{\prime}$ are always negative; this means that oscillation in the y direction will not become unstable. These results agree qualitatively with the general experimental observations (Zdravkovich 1982).

The natural frequencies of constrained modes are affected by $\alpha_{j \mathrm{j}}^{\prime \prime}$ and $\beta_{\mathrm{jj}}^{\prime \prime}$. When the fluid-stiffness coefficient is positive, the frequency is reduced. The regions in which $\alpha_{11}^{\prime \prime}$ and $\alpha_{22}^{\prime \prime}$ are positive are given in Table 2. Fluid stiffness for oscillations in the $\mathrm{y}$ direction, $\beta_{\mathrm{jj}}$, is negative for two tubes normal to flow and the upstream tube. The downstream tube, $\beta_{22}^{\prime \prime}$, becomes positive when $U_{\mathrm{r}}$ is $>8.2$.

\section{Coupled Vibration}

In flowing fluid, from Eqs. 15 and 16 the natural frequencies and modal damping ratios of the system can be calculated as follows: 


$$
\begin{aligned}
& f=f\left(\gamma, \zeta_{v}, U_{v}\right), \\
& \zeta=\zeta\left(\gamma, \zeta_{v}, U_{v}\right) .
\end{aligned}
$$

It should be noted that the fluid-damping and fluid-stiffness coefficients are functions of $U_{r}(=U / f D)$; therefore, a numerical method is needed to calculate $f$ and $\zeta$.

Stability of a cylinder array is determined from Eqs. 15 and 16. The nondimensional parameters in Eqs. 15 and 16 are $\gamma, \zeta_{v}, U_{v}, \alpha_{j k}, \sigma_{j k}, \tau_{j k}, \beta_{j k}, \alpha_{j k}^{\prime}, \sigma_{j k}^{\prime}$, $\tau_{j k}^{\prime}, \beta_{j k}^{\prime}, \alpha_{j k}^{\prime \prime}, \sigma_{j k}^{\prime \prime}, \tau_{j k}^{\prime \prime}$, and $\beta_{j k}^{\prime \prime}$. Therefore, the critical flow velocity can be written in a functional form as

$$
\begin{aligned}
U_{v}= & F\left(\gamma, \zeta_{v}, \omega_{v} / \omega, \alpha_{j k}, \sigma_{j k}, \tau_{j k}, \beta_{j k},\right. \\
& \left.\alpha_{j k}^{\prime}, \sigma_{j k}^{\prime}, \tau_{j k}^{\prime}, \beta_{j k}^{\prime}, \alpha_{j k}^{\prime \prime}, \sigma_{j k}^{\prime \prime}, \tau_{j k}^{\prime \prime}, \beta_{j k}^{\prime \prime}\right) .
\end{aligned}
$$

For two tubes, if fluid-force coefficients are independent of $U_{r}$, then

$$
\mathrm{U}_{\mathrm{v}}=\mathrm{F}\left(\gamma, \zeta_{\mathrm{v}}\right)
$$

or,

$$
\mathrm{U}_{\mathrm{r}}=\frac{\mathrm{f}_{\mathrm{v}}}{\mathrm{f}} \mathrm{F}\left(\gamma, \zeta_{\mathrm{v}}\right)
$$

i.e., the critical flow velocity is a function of mass ratio and damping ratio only. 


\section{Fluidelastic Instabllity in Light Fluid}

In a light fluid, fluid inertia and damping associated with the quiescent fluid can be neglected. Equations 15 and 16 can be written

$$
\begin{aligned}
\ddot{a}_{j} & +2 \zeta_{v} \omega_{v} \dot{a}_{j}+\omega_{v}^{2} a_{j}-\frac{\gamma}{\pi^{3}} U_{v}^{2} \sum_{k=1}^{2}\left[\frac{\omega_{v}^{2}}{\omega}\left(\alpha_{j k} \dot{a}_{j k}+\sigma_{j k}^{\prime} b_{k}\right)\right. \\
& \left.+\omega_{v}^{2}\left(\alpha_{j k}^{n} a_{k}+\sigma_{j k}^{n} b_{k}\right)\right]=p_{j} \\
\ddot{b}_{j} & +2 \zeta_{v} \omega_{v} \dot{b}_{j}+\omega_{v}^{2} b_{j}-\frac{\gamma}{\pi^{3}} U_{v}^{2} \sum_{k=1}^{2}\left[\frac{\omega_{v}^{2}}{\omega}\left(\tau_{j k} \dot{a}_{j k}+\beta_{j k} b_{k}\right)\right. \\
& \left.+\omega_{v}^{2}\left(\tau_{j k}^{n} a_{k}+\beta_{j k}^{n} b_{k}\right)\right]=q_{j} .
\end{aligned}
$$

All fluid-force coefficients in a light fluid are approximately independent of $U_{r}$, and the oscillation frequency is approximately equal to $\omega_{\mathrm{v}}\left(i . e ., \omega_{\mathrm{v}}=\omega_{\mathrm{f}}\right)$. Then $\gamma \mathrm{U}_{\mathrm{v}}^{2}$ plays the same role as $\zeta_{\mathrm{V}}$; both contribute to system damping. Modal damping for a particular mode can be written

$$
\zeta=\zeta_{\mathrm{v}}-\mathrm{C} \gamma \mathrm{U}_{\mathrm{v}}^{2}
$$

where $\mathrm{C}$ depends on fluid-damping and fluid-stiffness coefficients. Instability occurs if $\zeta=0$; i.e.,

$$
\mathrm{U}_{\mathrm{v}}=\frac{1}{\mathrm{C}}\left(\frac{\zeta_{\mathrm{v}}}{\gamma}\right)^{0.5}
$$

or 


$$
\frac{U}{f_{v} \mathrm{D}} \propto\left(\frac{2 \pi \zeta_{\mathrm{v}} \mathrm{m}}{\rho D^{2}}\right)^{0.5}
$$

Thus, the critical flow velocity is a function of the mass-damping parameter and is proportional to its half-power.

\section{CLOSING REMARKS}

In the past, the motion-dependent fluid forces for two tubes were not quantified in general. In this study, fluid-damping and fluid-stiffness coefficients for two tubes normal to flow and two tubes in tandem with the pitch-to-diameter ratio of 1.35 are presented as a function of reduced flow velocity for a series of Reynolds numbers. At high reduced flow velocity, the fluid-force coefficients are practically independent of reduced flow velocity. However, at low reduced flow velocity, fluid-damping and fluid-stiffness coefficients depend on reduced flow velocity, Reynolds number, and oscillation amplitude.

Once fluid damping and fluid stiffness are known, the response of two tubes in crossflow can be predicted on the basis of the unsteady-flow theory. Fluid damping and fluid stiffness play an important role in determining tube response. The system may become unstable due to motion-dependent fluid forces. For example, fluiddamping-controlled instability can occur even in the constrained mode.

The force transducers used to measure motion-dependent fluid forces in this test were designed for the low flow velocity range. For different flow conditions with different flow velocity and water channel depth, new force transducers will be needed. It is important to design a force transducer so that it is sensitive but rigid enough to resist flow excitation; it is a delicate balance of sensitivity and rigidity. 
Various approximate theories, some ignoring fluid coupling and some ignoring fluid stiffness, for two tubes in crossflow are useful in specific conditions. The unsteady-flow theory presented in this paper accounts for the interaction of tube motions and flow field adequately; it can be applied to various conditions. The key elements of the unsteady-flow theory are the motion-dependent fluid forces. An extensive effort is needed to obtain these forces experimentally. Some studies have been published to calculate these forces numerically (Sadaoka and Umegaki 1993, Ichioka et al. 1994). It is expected that once developed, the computational fluid dynamics method will be more economical.

\section{ACKNOWLEDGMENTS}

This work was jointly funded by the U.S. Department of Energy, Office of Basic Energy Sciences, Division of Engineering and Geosciences, under Contract W-31109-Eng-38, and by Taiwan Power Company under an agreement with the U.S. Department of Energy, Contract Agreement 31-109-Eng-38-85847.

\section{REFERENCES}

Chen, S. S., 1975, "Vibration of Nuclear Fuel Bundles," Nuclear Engineering and Design, Vol. 35, pp. 399-422.

Chen, S. S., 1986, "A Review of Flow-Induced Vibration of Two Circular Cylinders in Crossflow," Journal of Pressure Vessel Technology, Vol. 108, pp. 382-393.

Chen, S. S., 1987, Flow-Induced Vibration of Circular Cylindrical Structures, Hemisphere Publishing Corp., New York. 
Chen, S. S., and Chandra, S., 1991, "Fluidelastic Instabilities in Tube Bundles Exposed to Nonuniform Cross-Flow," Journal of Fluids and Structures, Vol. 5, pp. 299-322.

Chen, S. S., and Jendrzejczyk, J. A., 1978, "Experiments on Fluidelastic Vibration of Cantilevered Tube Bundles," Journal of Mechanical Design, Vol. 110, pp. 540-548.

Chen, S. S., Zhu, S., and Cai, Y., 1995, "An Unsteady Flow Theory for Vortex Induced Vibration," Journal of Sound and Vibration, in press.

Chen, S. S., Zhu, S., and Jendrzejczyk, J. A., 1994, "Fluid Damping and Fluid Stiffness of a Tube Row in Crossflow," Journal of Pressure Vessel Technology, Vol. 116, pp. 370-383.

Ichioka, T., Kawata, Y., and Izumi, H., 1994, "Two-Dimensional Flow Analysis of Fluid Structure Interaction Around a Cylinder and a Row of Cylinders," ASME Publication, PVP-Vol. 273, pp. 33-41.

Sadaoka, N., and Umegaki, K., 1993, "A Numerical Method to Calculate FlowInduced Vibrations in a Turbulent Flow," ASME Publication, PVP-Vol. 258, pp. 8394.

Zdravkovich, M. M., 1977, "Review of Flow Interference between Two Circular Cylinders in Various Arrangements," Journal of Fluids Engineering, Vol. 99, pp. 618-633.

Zdravkovich, M. M., 1982, "Flow Induced Oscillations of Two Interfering Circular Cylinders," International Conference on Flow Induced Vibrations in Fluid Engineering, Reading, England, Sept. 14-16, Paper No. D2. 
Zdravkovich, M. M., 1991, "On Suppressing Metastable Flow behind a Tube Array," 5th International Conference on Flow Induced Vibrations, IMchE, 1991-6, pp. $185-190$. 
Table 1. Regions of reduced flow velocity in which fluiddamping coefficients $\alpha_{11}^{i}$ and $\alpha_{22}$ are positive

\begin{tabular}{ccc}
\hline Fluid-Damping Coefficients & $\begin{array}{c}\text { Flow Velocity } \\
(\mathrm{m} / \mathrm{s})\end{array}$ & $\begin{array}{c}\text { Reduced Flow } \\
\text { Velocity }\end{array}$ \\
\hline Two Tubes Normal to Flow & & \\
$\alpha_{11}^{\prime}$ or $\alpha_{22}^{\prime}$ & 0.05 & 1.7 to 4.3 \\
& 0.07 & 1.8 to 4.7 \\
Two Tubes in Tandem & $>0.13$ & 2.3 to 5.6 \\
$\alpha_{11}^{\prime}$ & & \\
& 0.07 & $>6.0$ \\
$\alpha_{22}^{\prime}$ & 0.11 & $>7.1$ \\
& 0.15 & $>7.4$ \\
& 0.07 & $>3.2$ \\
& 0.11 & $>3.6$ \\
\hline
\end{tabular}


Table 2. Regions of reduced flow velocity in which fluidstiffness coefficients $\alpha_{11}^{\prime \prime}$ and $\alpha_{22}^{\prime \prime}$ are positive

\begin{tabular}{ccc}
\hline Fluid-Stiffness Coefficients & $\begin{array}{c}\text { Flow Velocity } \\
(\mathrm{m} / \mathrm{s})\end{array}$ & $\begin{array}{c}\text { Reduced Flow } \\
\text { Velocity }\end{array}$ \\
\hline Two Tubes Normal to Flow & & \\
$\alpha_{11}^{\prime \prime}$ or $\alpha_{22}^{\prime \prime}$ & 0.05 & $<1.7$ \\
& 0.07 & $<2.1$ \\
& 0.113 & $<2.5$ \\
& 0.146 & $<3.2$ \\
Two Tubes in Tandem & 0.166 & $<3.4$ \\
$\alpha_{11}^{\prime \prime}$ & & \\
& 0.07 & $>12.5$ \\
$\alpha_{22}^{\prime \prime}$ & 0.11 & $>14.0$ \\
& 0.15 & $>15.8$ \\
& 0.07 & $>1.8$ \\
& 0.11 & $>2.2$ \\
& 0.15 & $>5.2$ \\
\hline
\end{tabular}




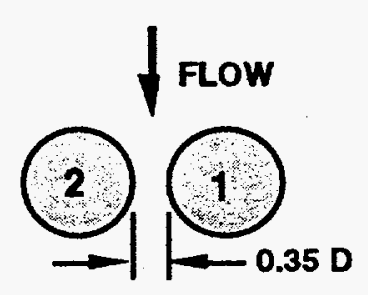

(a) TWO TUBES NORMAL TO FLOW

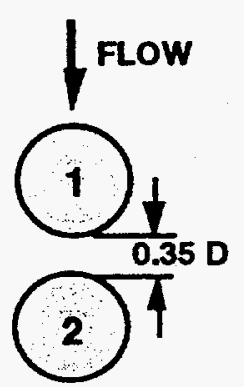

(b) TWO TUBES IN TANDEM

Fig. 1. Arrangements of two tubes in crossflow used in this study 

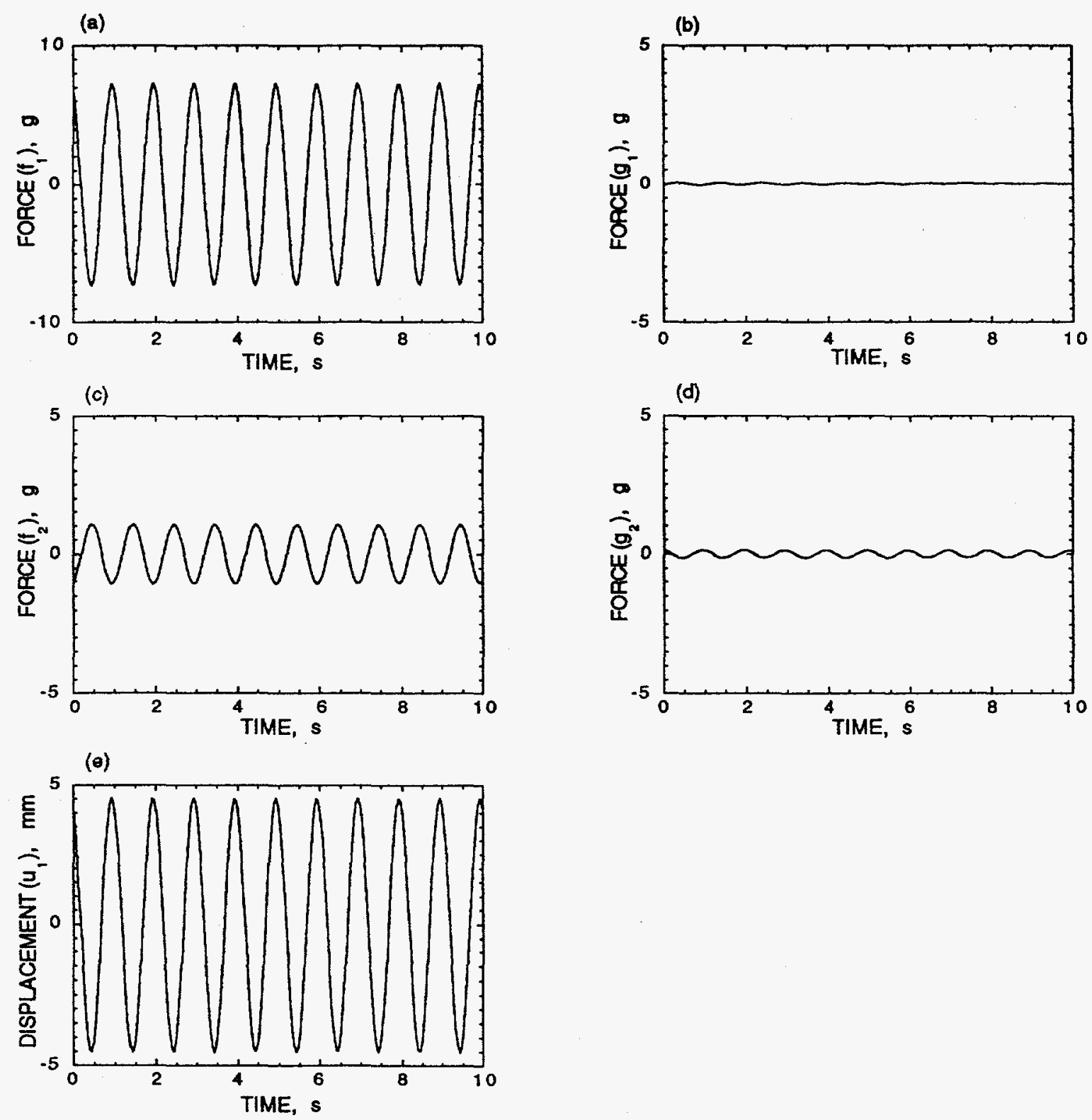

Fig. 2. Motion-dependent fluid forces $f_{1}$ (Fig. 2a), $g_{1}$ (Fig. 2b), $f_{2}$ (Fig. 2c), and $g_{2}$ (Fig. 2d), acting on two tubes with pitch-to-diameter ratio of 1.35 (Fig. 1a) due to motion $\mathrm{u}_{1}$ (Fig. 2e) 

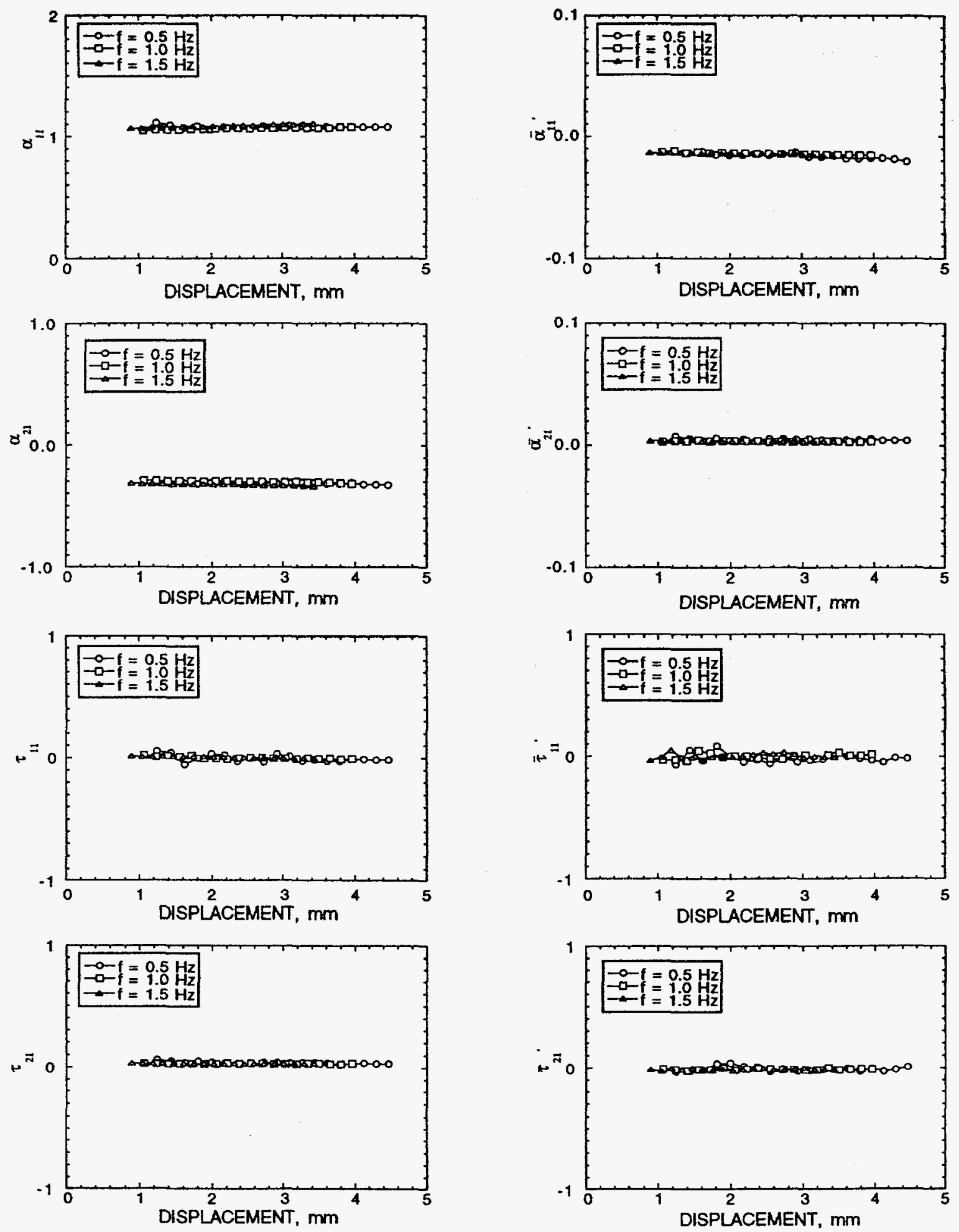

Fig. 3. Added mass coefficients, $\alpha_{11}, \alpha_{21}, \tau_{11}$, and $\tau_{21}$, and fluid-damping coefficients, $\bar{\alpha}_{11}^{\prime}, \bar{\alpha}_{21}^{\prime}, \bar{\tau}_{11}^{\prime}$, and $\bar{\tau}_{21}^{\prime}$ 

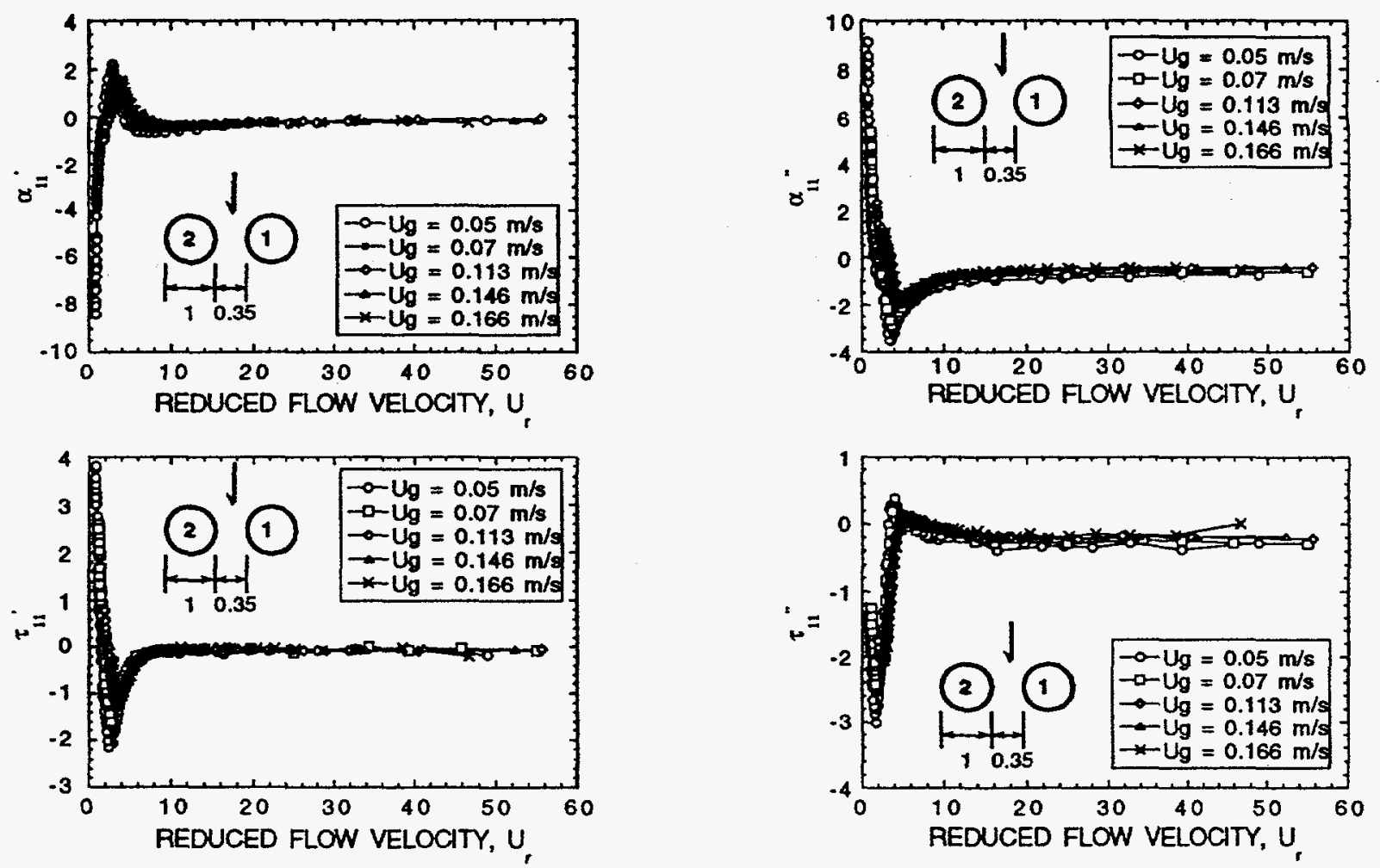

Fig. 4. Fluid-damping and fluid-stiffness coefficients $\alpha_{11}^{\prime}, \tau_{11}^{\prime}, \alpha_{11}^{\prime \prime}$, and $\tau_{11}^{\prime \prime}$ for two tubes normal to flow 

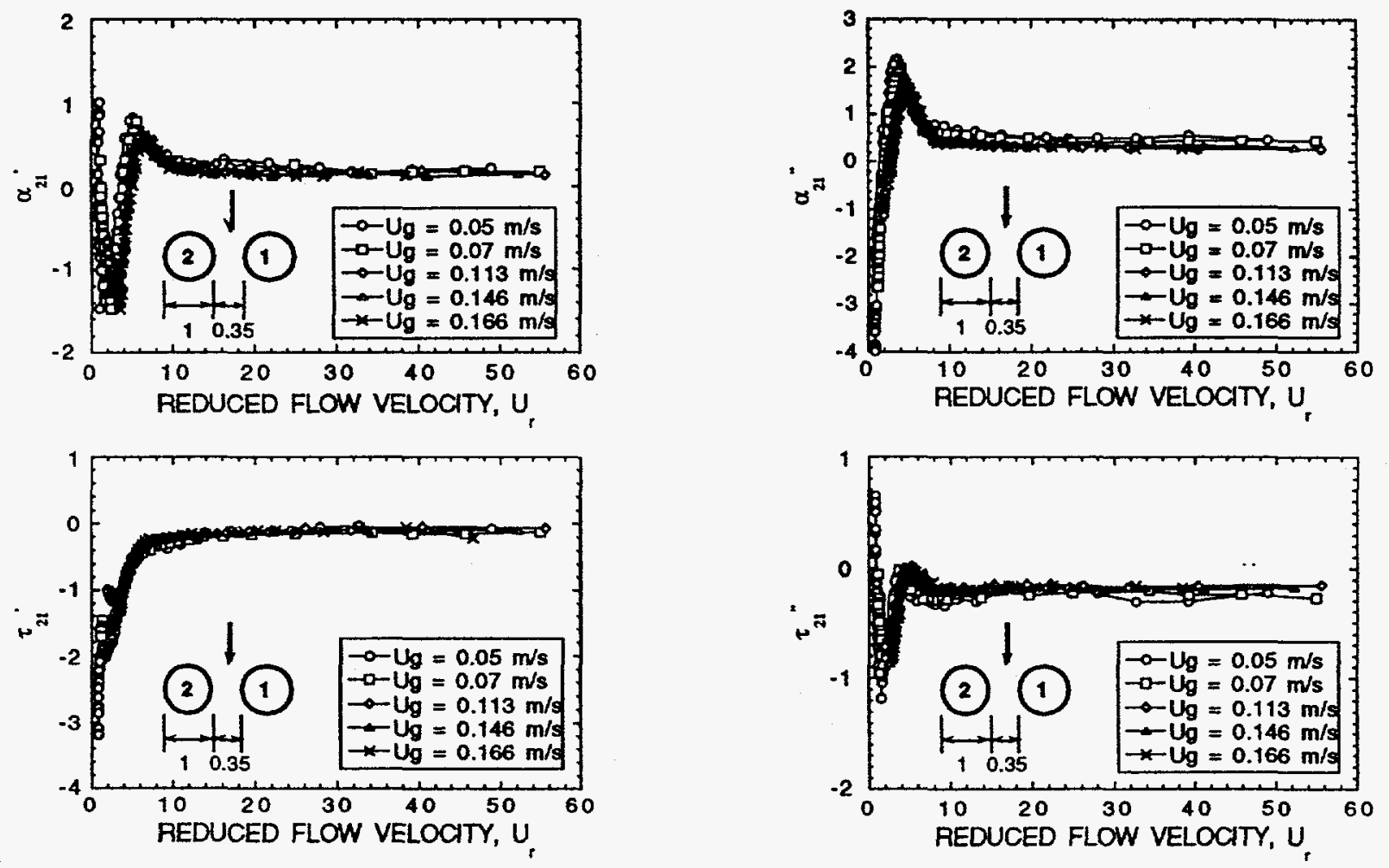

Fig. 5. Fluid-damping and fluid-stiffness coefficients $\alpha_{21}^{\prime}, \tau_{21}^{\prime}, \alpha_{21}^{\prime \prime}$, and $\tau_{21}^{\prime \prime}$ for two tubes normal to flow 

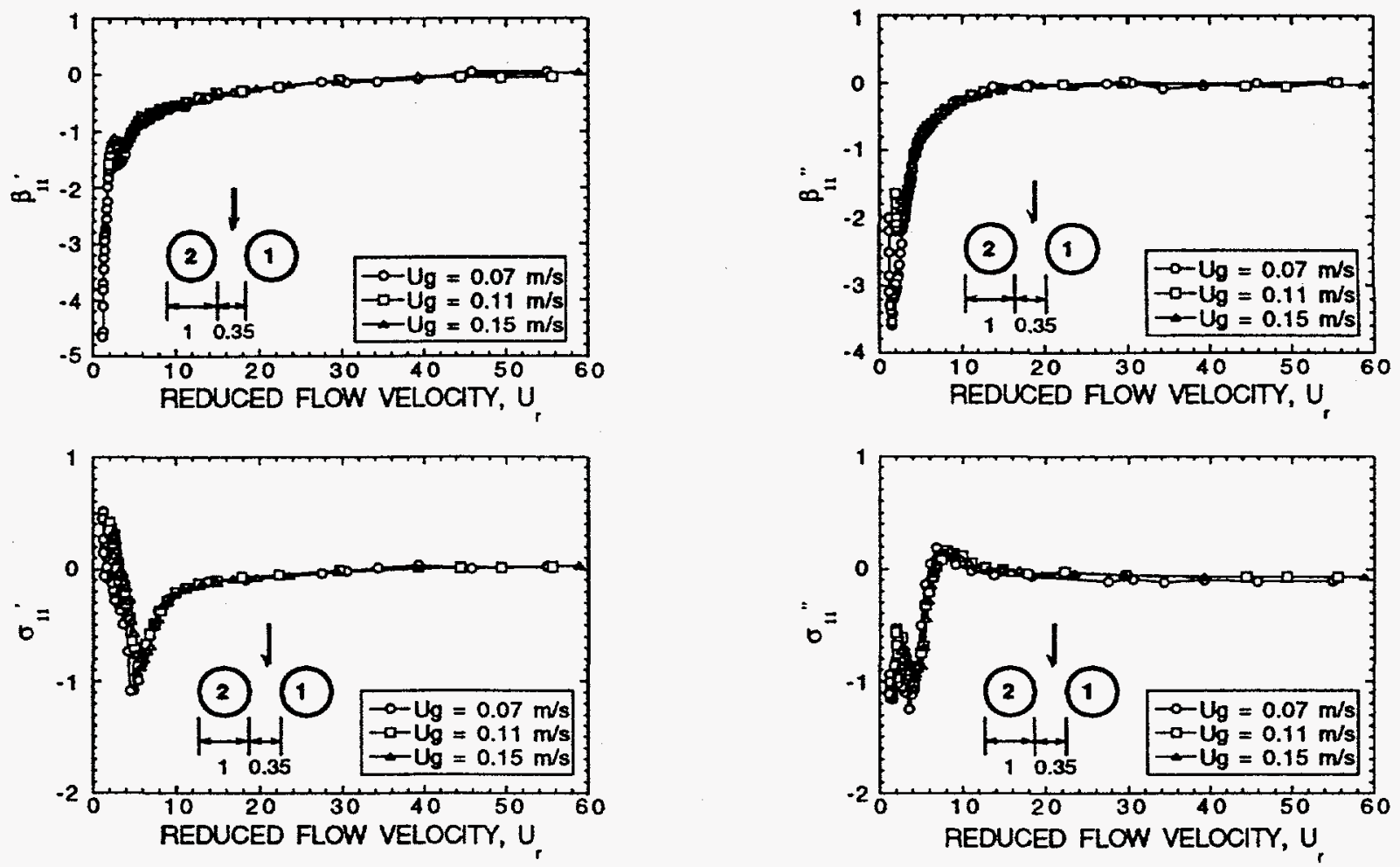

Fig. 6. Fluid-damping and fluid-stiffness coefficients $\beta_{11}^{\prime}, \sigma_{11}^{\prime}, \beta_{11}^{\prime \prime}$, and $\sigma_{11}^{\prime \prime}$ for two tubes normal to flow 

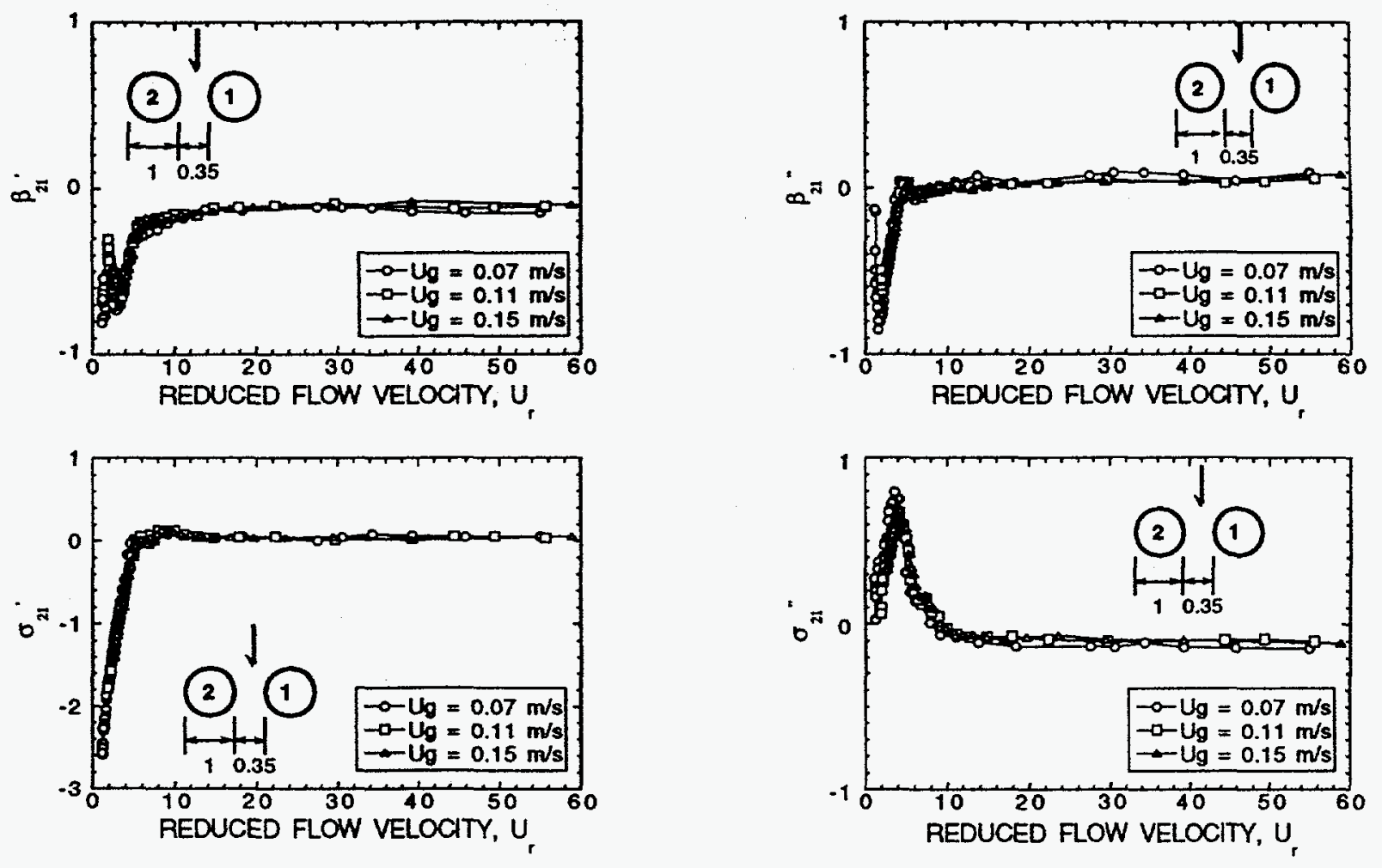

Fig. 7. Fluid-damping and fluid-stiffness coefficients $\beta_{21}^{\prime}, \sigma_{21}^{\prime}, \beta_{21}^{\prime \prime}$, and $\sigma_{21}^{\prime \prime}$ for two tubes normal to flow 

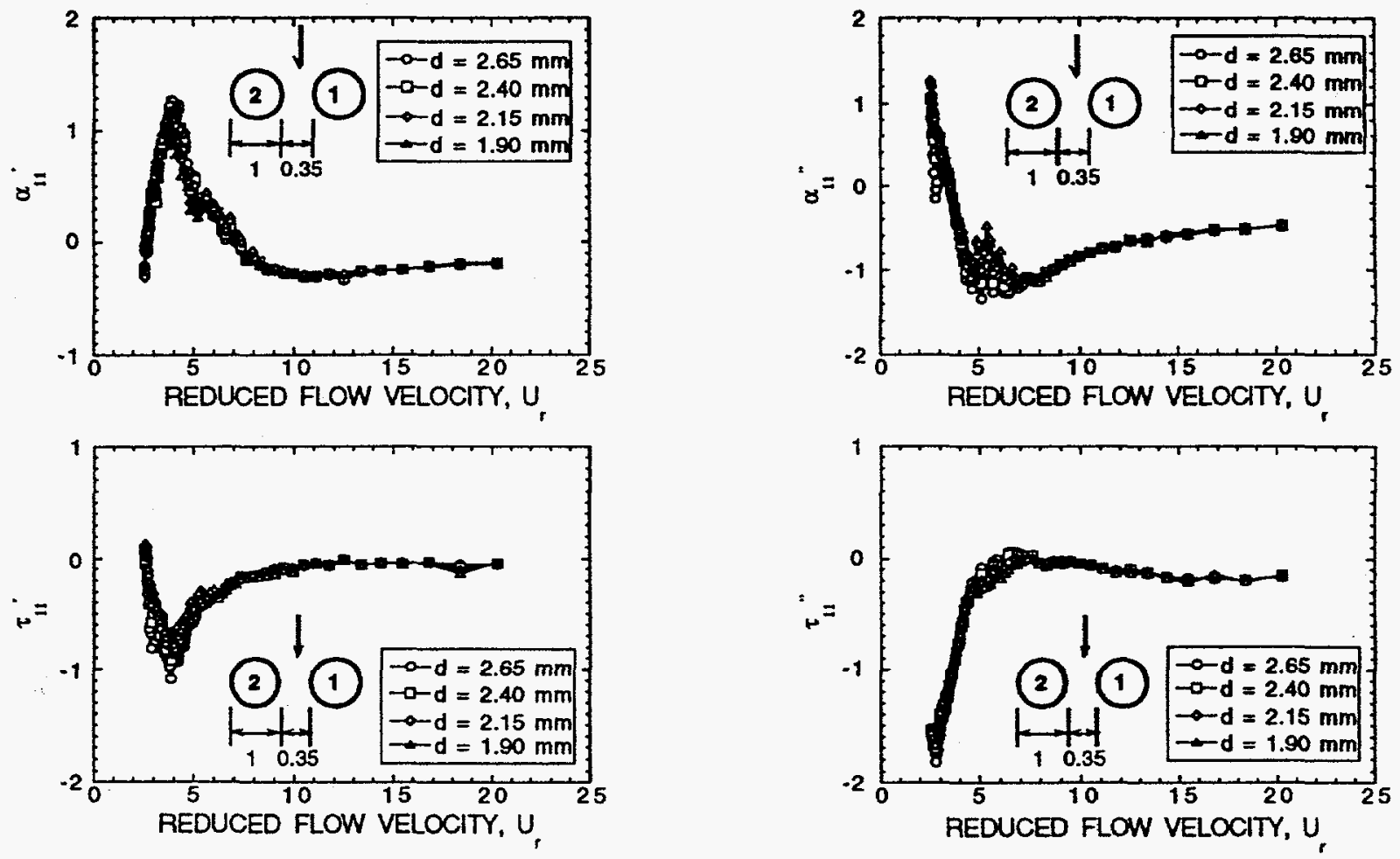

Fig. 8. Fluid-damping and fluid-stiffness coefficients $\alpha_{11}^{\prime}, \tau_{11}^{\prime}, \alpha_{11}^{\prime \prime}$, and $\tau_{11}^{\prime \prime}$ as a function of excitation amplitude for two tubes normal to flow 

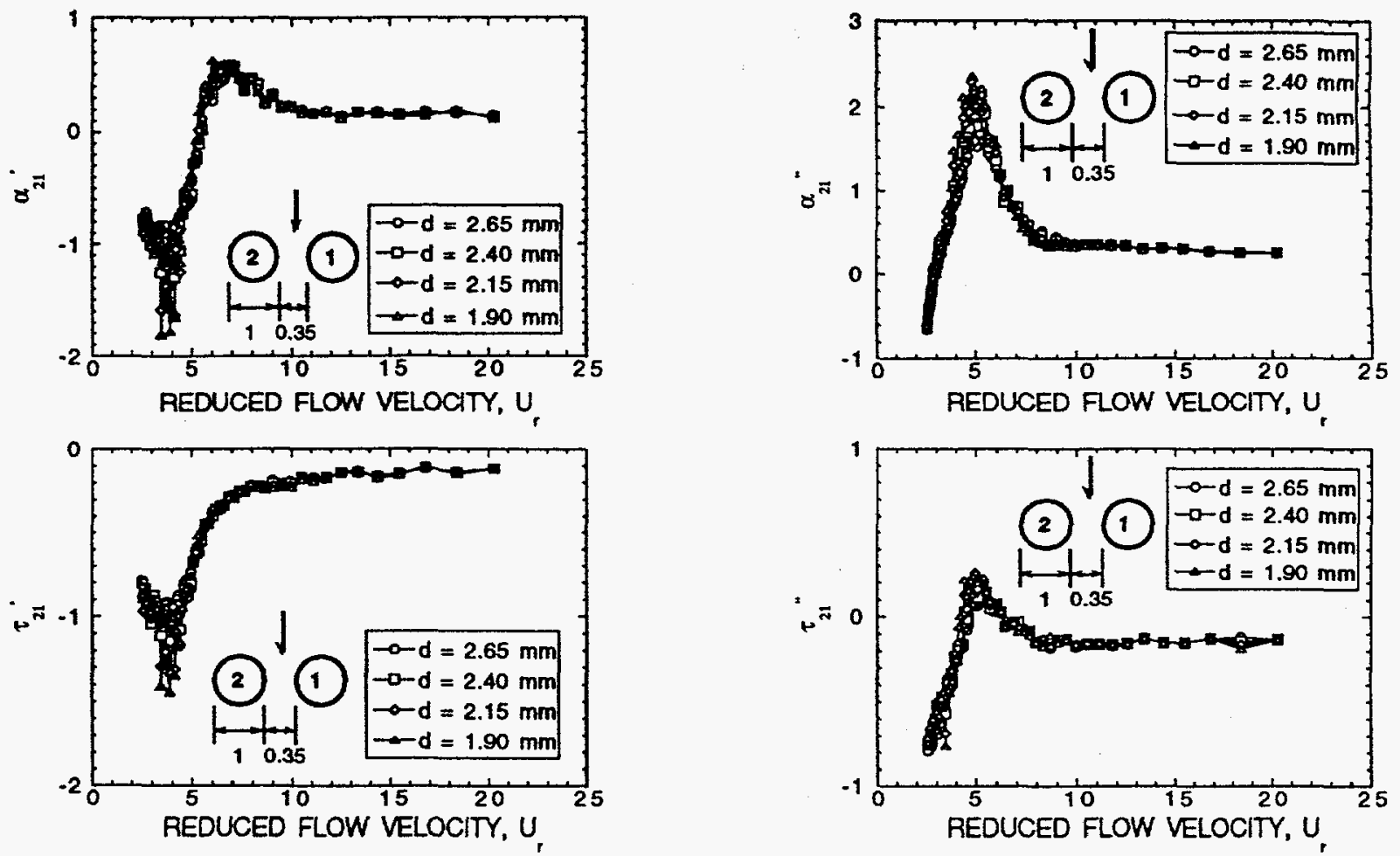

Fig. 9. Fluid-damping and fluid-stiffness coefficients $\alpha_{21}^{\prime}, \tau_{21}^{\prime}, \alpha_{21}^{\prime \prime}$, and $\tau_{21}^{\prime \prime}$ as a function of excitation amplitude for two tubes normal to flow 

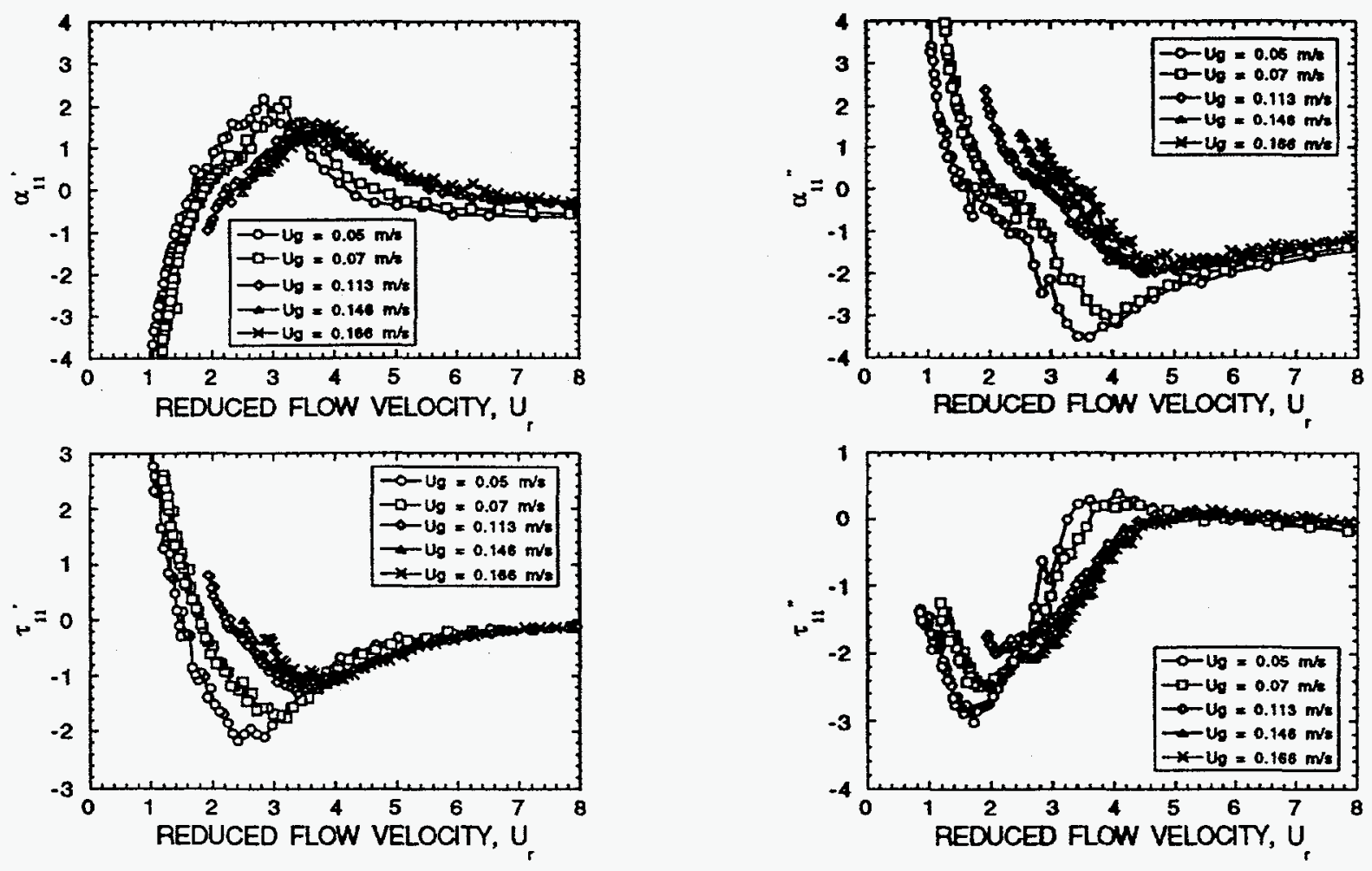

Fig. 10. Fluid-damping and fluid-stiffness coefficients $\alpha_{11}^{\prime}, \tau_{11}^{\prime}, \alpha_{11}^{\prime \prime}$, and $\tau_{11}^{\prime \prime}$ for two tubes normal to flow 


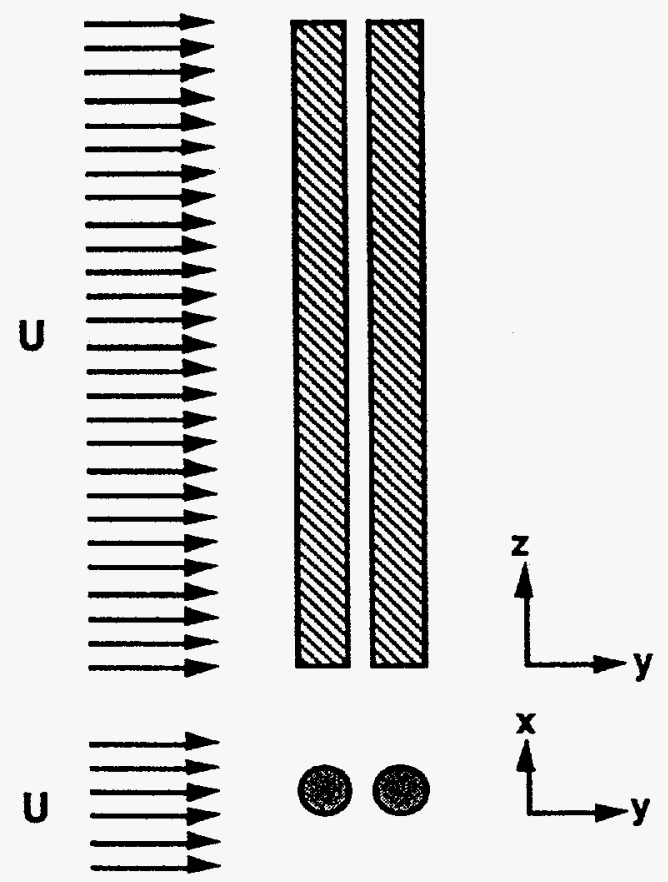

Fig. 11. Two identical tubes subjected to crossflow

\section{DISCLAIMER}

This report was prepared as an account of work sponsored by an agency of the United States Government. Neither the United States Government nor any agency thereof, nor any of their employees, makes any warranty, express or implied, or assumes any legal liability or responsibility for the accuracy, completeness, or usefulness of any information, apparatus, product, or process disclosed, or represents that its use would not infringe privately owned rights. Reference herein to any specific commercial product, process, or service by trade name, trademark, manufacturer, or otherwise does not necessarily constitute or imply its endorsement, recommendation, or favoring by the United States Government or any agency thereof. The views and opinions of authors expressed herein do not necessarily state or reflect those of the United States Government or any agency thereof. 


\section{DISCLAMIER}

Portions of this document may be illegible in electronic image products. Images are produced from the best available original document. 